\title{
Naringin inhibits colorectal cancer cell growth by repressing the PI3K/AKT/mTOR signaling pathway
}

\author{
HONGYUN CHENG $^{1 *}$, XUE JIANG $^{1 *}$, QIAN ZHANG ${ }^{1 *}$, JUN MA $^{2}$, RONGHUI CHENG ${ }^{1}$, \\ HONGMEI YONG ${ }^{1}$, HUICHANG SHI ${ }^{1}$, XUEYI ZHOU ${ }^{1}$, LIYUE GE ${ }^{1}$ and GUANGYI GAO ${ }^{1}$ \\ Departments of ${ }^{1}$ Traditional Chinese Medicine and ${ }^{2}$ Oncology, Huai'an Second People's Hospital, \\ The Affiliated Huai'an Hospital of Xuzhou Medical University, Huai'an, Jiangsu 223001, P.R. China
}

Received June 26, 2019; Accepted March 10, 2020

DOI: $10.3892 / \mathrm{etm} .2020 .8649$

\begin{abstract}
In recent years, the incidence of colorectal cancer (CRC) has increased and research into new treatment methods for CRC has become a hot topic. Naringin has an inhibitory effect on the PI3k/AKT/mTOR signaling pathway in various tumor cell types and the effect of naringin is closely related to the occurrence and proliferation of tumor cells. The aim of this present study was to investigate whether naringin could inhibit the proliferation of CRC cells by inhibiting the PI3K/AKT/mTOR signaling pathway. This could provide a more mechanism-based treatment for CRC. MTT assays were used to detect the proliferation of CRC cells treated with various concentrations of naringin. The degree of apoptosis and the expression of apoptosis-related proteins (Bcl-2 and Bax) in CRC cells stimulated by naringin was detected using flow cytometry and western blot assays, respectively. The expression levels of PI3K/AKT/mTOR-related proteins [PI3K, AKT, mTOR, phosphorylated (p)-PI3K, p-AKT and p-mTOR] after naringin stimulation in CRC cells were detected using western blot assays. Naringin inhibited the proliferation of CRC cells in a dose-dependent manner. Naringin promoted the apoptosis of CRC cells and inhibited the activation of the PI3K/AKT/mTOR signaling pathway in a dose-dependent manner. The results demonstrated that naringin may be a promising therapeutic agent for the treatment of CRC, which may inhibit the proliferation of CRC cells and induce apoptosis by inhibiting the PI3K/AKT/mTOR signaling pathway.
\end{abstract}

Correspondence to: Dr Liyue Ge or Dr Guangyi Gao, Department of Traditional Chinese Medicine, Huai'an Second People's Hospital, The Affiliated Huai'an Hospital of Xuzhou Medical University, 62 Huaihai South Road, Huai'an, Jiangsu 223001, P.R. China

E-mail: geliyue2602@163.com

E-mail: gaogy190626@163.com

${ }^{*}$ Contributed equally

Key words: colorectal cancer, naringin, PI3K/AKT/mTOR pathway

\section{Introduction}

Colorectal cancer (CRC) is one of the most comment malignant tumor types and the second most common cancer in females worldwide in 2012 (1). In recent years, due to environmental and dietary effects, the number of patients suffering from CRC has increased annually (2). Currently, the primary methods for treating CRC are surgery, radiotherapy and chemotherapy $(3,4)$. Furthermore, following surgery, patients often have reduced gastrointestinal function, reduced immunity and also require cumbersome nursing care (5). As a result, the pain caused by subsequent radiotherapy and chemotherapy also increases (6). Therefore, targeted drugs play an important role in the treatment of CRC (7-11). Commonly used targeted drugs for the treatment of CRC are those targeting the epidermal growth factor receptor and targeting vascular endothelial growth factor (VEGF) (12). However, due to problems arising from drug resistance (13), it is important to investigate further effective compounds targeting alternative signaling pathways.

Frydoonfar et al (14) found that naringenin had a significant inhibitory effect on colon cancer cell proliferation and that $0.71 \mathrm{mM}$ naringenin significantly inhibited colon cell proliferation. This highlighted naringenin as a promising compound for further investigation. Naringin is a dihydroflavonoid with a variety of biological activities such as anti-oxidation, anti-inflammation, anti-mutation and analgesic activities (15). Furthermore, previous studies have found that naringin inhibits the proliferation of breast cancer and cervical cancer cells (16-19). In addition, naringin can inhibit the biological function of tumors by inhibiting the excessive activation of the PI3K/AKT/mTOR signaling pathway (20). In recent years, the PI3K/AKT/mTOR signaling pathway has been identified as a key target of tumor-targeted therapy (21-24). The $\mathrm{PI} 3 \mathrm{~K} / \mathrm{AKT} / \mathrm{mTOR}$ signaling pathway is important to regulate the proliferation, growth, migration and survival of tumor cells $(25,26)$. It has been reported that the occurrence of CRC is linked to the PI3K/AKT/mTOR signaling pathway $(27,28)$. Moreover, $60-70 \%$ of colon cancer patients present AKT signaling activation and a reduction in PTEN expression levels (28). A previous study has found that the expression levels of phosphorylated (p)-AKT are higher in CRC lesions or metastatic lesions and the probability of raised mTOR 
expression levels was also increased following PI3K mutations and the loss of PTEN expression (27).

Based on these findings, this present study aimed to investigate whether naringin could inhibit the proliferation of CRC cells by inhibiting the PI3K/AKT/mTOR signaling pathway, so as to potentially provide a more mechanisms-based treatment for CRC.

\section{Materials and methods}

Materials. Naringin was purchased from Beijing Solarbio Science \& Technology Co., Ltd. Human HCT116 and SW620 CRC cell lines were purchased from The Cell Bank of Type Culture Collection of the Chinese Academy of Sciences.

Cell culture. HCT116 cells were maintained in McCoy's 5A medium (Gibco; Thermo Fisher Scientific, Inc.) and SW620 cells were maintained in L-15 medium (Gibco; Thermo Fisher Scientific, Inc.). Both media were supplemented with $10 \%$ FBS (Gibco; Thermo Fisher Scientific, Inc.) and the cells were cultured at $37^{\circ} \mathrm{C}$ in a $5 \% \mathrm{CO}_{2}$ incubator.

MTT assay. Cells (5x104 cells/well) were seeded into 96-well plates and cultured for $24 \mathrm{~h}$, then supplemented with fresh medium for naringin treatment. After the cells were incubated with naringin $(0,6,12$ or $25 \mu \mathrm{g} / \mathrm{ml})(29)$ for 24,48 and $72 \mathrm{~h}$, the medium was removed and $30 \mu 1$ MTT $(0.5 \mathrm{mg} / \mathrm{ml})$ was added to each well, prior to further incubation for $4 \mathrm{~h}$. Subsequently, $100 \mu 1$ DMSO (Sigma-Aldrich; Thermo Fisher Scientific, Inc.) was added to each well. The optical density values were then measured at $490 \mathrm{~nm}$ using a micro-plate reader (BioTek China).

Measurement of cell apoptosis using flow cytometry. After incubation with naringin $(0,6,12$ or $25 \mu \mathrm{g} / \mathrm{ml})$ for $48 \mathrm{~h}$ in 6 -well plates $\left(5 \times 10^{4}\right.$ cells/well $)$, the cells were collected using trypsin digestion without EDTA and then centrifugated at room temperature at $1,000 \mathrm{x}$ g for $5 \mathrm{~min}$. Subsequently, the cells were re-suspended in $300 \mu \mathrm{l}$ of $1 \mathrm{X}$ binding buffer (Beyotime Institute of Biotechnology). A total of $5 \mu \mathrm{l}$ of Annexin V-FITC (Beyotime Institute of Biotechnology) was the added to the samples and mixed for $15 \mathrm{~min}$ at room temperature in the dark. Subsequently, $5 \mu 1$ of propidium iodide (Beyotime Institute of Biotechnology) was added for $5 \mathrm{~min}$. The samples were analyzed using a flow cytometer (FACSCalibur; BD Biosciences). FlowJo software (version 7.6.1; FlowJo LLC) was used to analyze the data.

Western blot assay. Cells in six-well plates (5x104 cells/well) were stimulated with naringin $(0,6,12$ or $25 \mu \mathrm{g} / \mathrm{ml})$ for $48 \mathrm{~h}$ and then washed with PBS. After the above procedure, the cellular proteins were harvested and lysed using RIPA buffer (Beyotime Institute of Biotechnology) at $4^{\circ} \mathrm{C}$ for $30 \mathrm{~min}$. A bicinchoninic acid protein assay kit (Pierce; Thermo Fisher Scientific, Inc.) was used to measure protein concentration. Samples (40 $\mu \mathrm{g} /$ lane) were separated on $12 \%$ SDS-polyacrylamide gels and transblotted onto a PVDF membrane by electroblotting. The PVDF membrane was blocked with 5\% skim milk for $2 \mathrm{~h}$ at room temperature. Subsequently, the membrane was incubated overnight with the following primary antibodies: Bcl-2 (1:1,000; cat. no. 4223; Cell Signaling Technology, Inc.), Bax

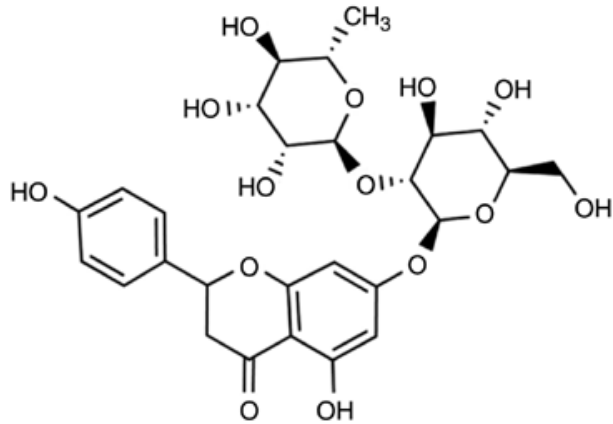

Figure 1. The structural formula of naringin.

(1:1,000; cat. no. 5023; Cell Signaling Technology, Inc.), PI3K (1:1,000; cat. no. 4257; Cell Signaling Technology, Inc.), phosphorylated (p)-PI3K (1:1,000; cat. no. 17366; Cell Signaling Technology, Inc.), AKT (1:1,000; cat. no. 9272; Cell Signaling Technology, Inc.), p-AKT (1:1,000; cat. no. 4060; Cell Signaling Technology, Inc.), mTOR (1:1,000; cat. no. 2972; Cell Signaling Technology, Inc.), p-mTOR (1:1,000; cat. no. 5536; Cell Signaling Technology, Inc.) and GAPDH (1:1,000; cat. no. 5174; Cell Signaling Technology, Inc.) at $4^{\circ} \mathrm{C}$, followed by incubation with horseradish peroxidase-conjugated anti-rabbit secondary antibody (1:2,000; cat. no. 7074; Cell Signaling Technology, Inc.) for $1 \mathrm{~h}$ at room temperature. The immunoreactive bands were visualized using an ECL detection kit (Thermo Fisher Scientific, Inc.). GAPDH signal was used to normalize protein loading. Band densities were quantified using Gel-Pro Analyzer densitometry software (version 6.3; Media Cybernetics, Inc.).

Statistical analysis. Data analyses were performed using SPSS 18.0 statistical software (SPSS, Inc.). The data are expressed as the mean $\pm \mathrm{SD}$ of $\geq 3$ separate experiments and the differences between groups were determined using unpaired Student's t-tests or one-way ANOVAs with Tukey's post hoc tests. $\mathrm{P}<0.05$ was considered to indicate a statistically significant difference.

\section{Results}

Naringin effectively inhibits the proliferation of CRC cells. The structural formula of naringin is shown in Fig. 1. To investigate the function of naringin in CRC, MTT assays were used to detect cell proliferation. The results showed that naringin had a significant inhibitory effect on the proliferation of CRC (SW620 and HCT116 cells) cells and showed a concentration-dependent effect (Fig. 2).

Naringin promotes apoptosis in CRC cells. It was demonstrated that naringin had an effect on apoptosis in CRC cells. The results of the apoptosis assay showed that naringin promoted the apoptosis of SW620 (Fig. 3A and B) and HCT116 cells (Fig. 3C and D). There also appeared to be a positive association between the concentration of naringin and the extent of apoptosis. Combined with the results of the western blot assays, this conclusion was further verified. The results of the western blot assays demonstrated that naringin effectively reduced the expression levels of $\mathrm{Bcl}-2$, an inhibitor 

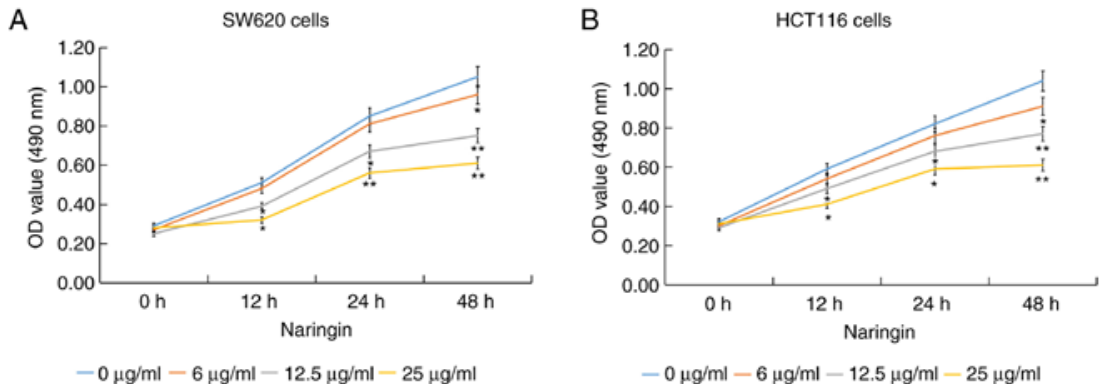

Figure 2. Effect of naringin on colorectal cancer cell proliferation. (A) SW620 and (B) HCT116 cells were treated with different concentrations (6, 12 or $25 \mu \mathrm{g} / \mathrm{ml}$ ) of naringin for 12,24 or $48 \mathrm{~h}$ at $37^{\circ} \mathrm{C}$. Cell proliferation was determined using MTT assays. Data are expressed as the mean $\pm \mathrm{SD}$. ${ }^{*} \mathrm{P}<0.05$ and ${ }^{* *} \mathrm{P}<0.01 \mathrm{vs} .0 \mu \mathrm{g} / \mathrm{ml}$ naringin treatment group. OD, optical density.
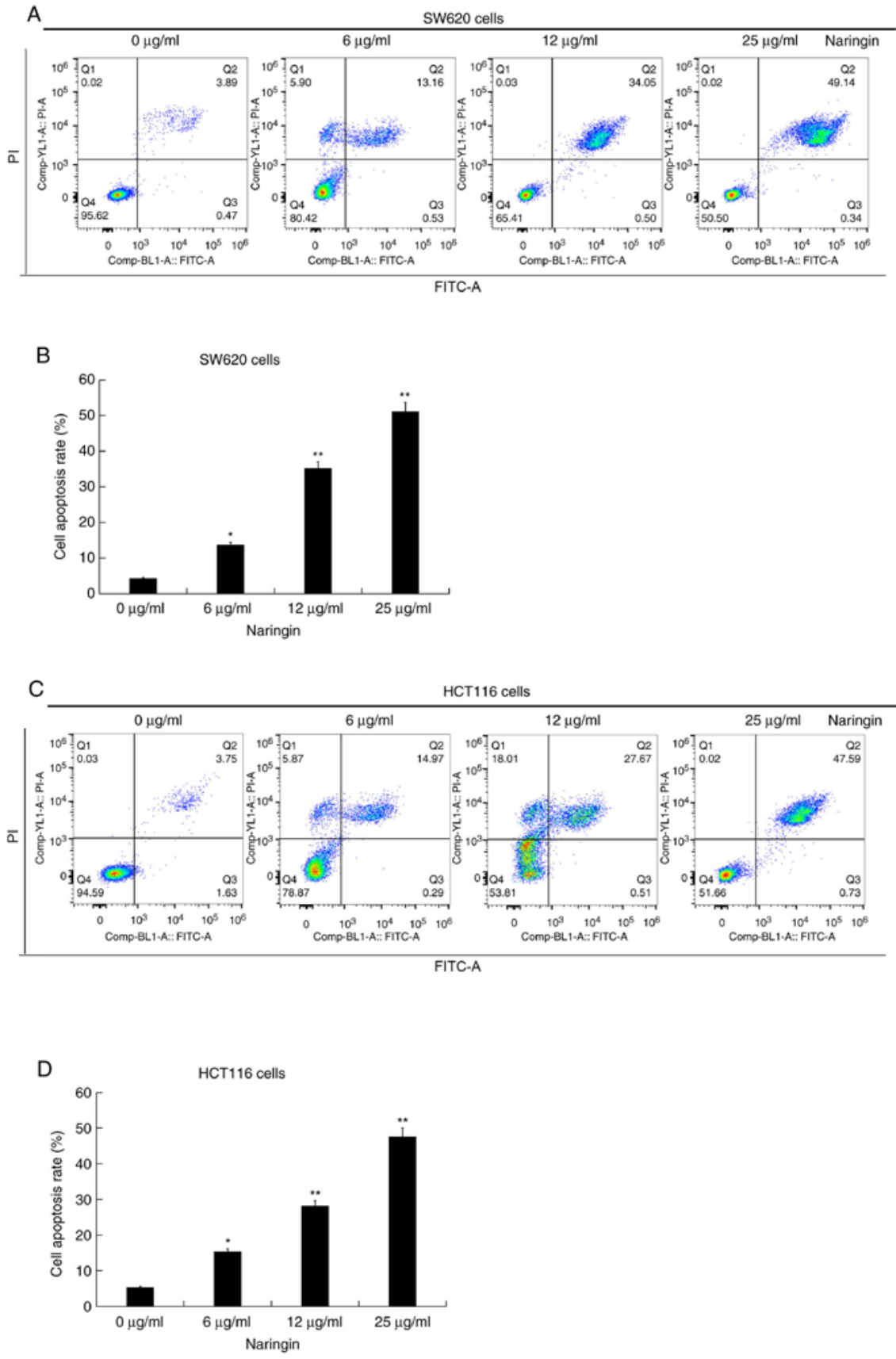

Figure 3. Effect of naringin on colorectal cancer cell apoptosis. (A) Representative flow cytometry graphs of SW620 cells treated with different concentrations $(6,12$ or $25 \mu \mathrm{g} / \mathrm{ml})$ of naringin for $48 \mathrm{~h}$ at $37^{\circ} \mathrm{C}$ and (B) the apoptosis rate was calculated following treatment. (C) Representative flow cytometry graphs of HCT116 cells treated with different concentrations $(6,12$ or $25 \mu \mathrm{g} / \mathrm{ml})$ of naringin for $48 \mathrm{~h}$ at $37^{\circ} \mathrm{C}$ and (D) the apoptosis rate was calculated following treatment. Data are presented as the mean \pm SD. ${ }^{*} \mathrm{P}<0.05$ and ${ }^{* *} \mathrm{P}<0.01 \mathrm{vs.} 0 \mu \mathrm{g} / \mathrm{ml}$ naringin treatment group. PI, propidium iodide. 

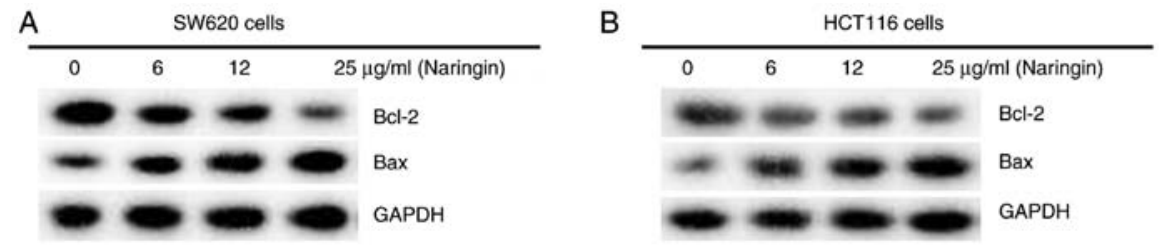

Figure 4. Effect of naringin on the expression levels of Bcl-2 and Bax in colorectal cancer cells. (A) SW620 and (B) HCT116 cells were treated with different concentrations $(6,12$ or $25 \mu \mathrm{g} / \mathrm{ml})$ of naringin for $48 \mathrm{~h}$ at $37^{\circ} \mathrm{C}$. Protein expression levels of Bcl-2 and Bax in cells were detected using western blotting.

A

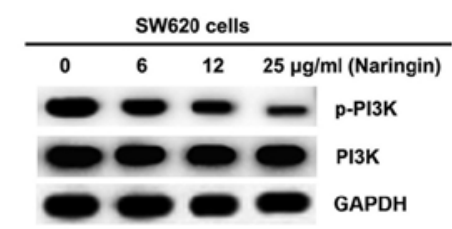

D

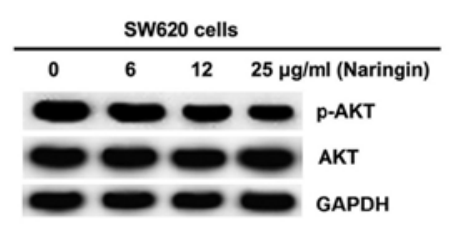

G

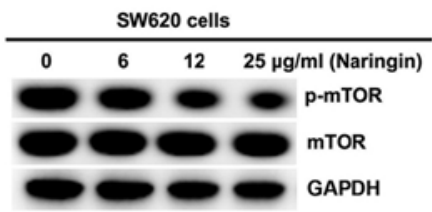

B
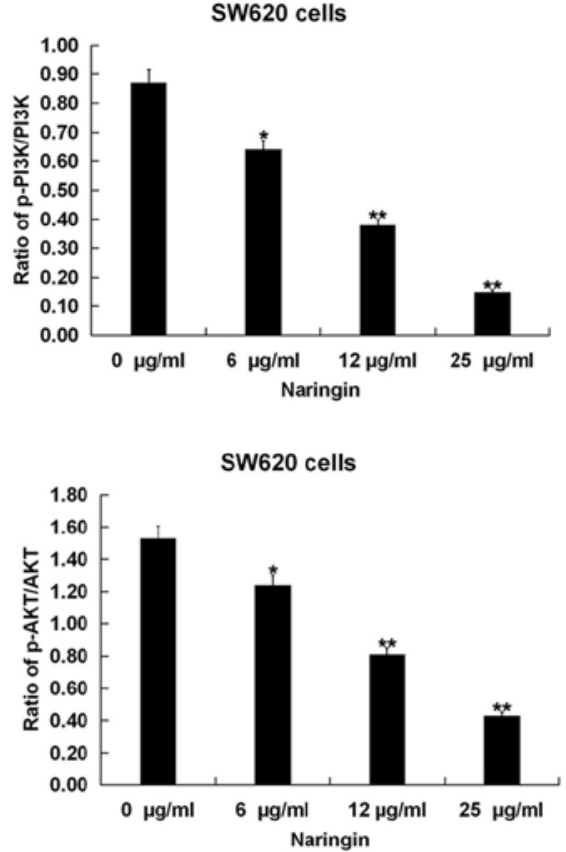

SW620 cells

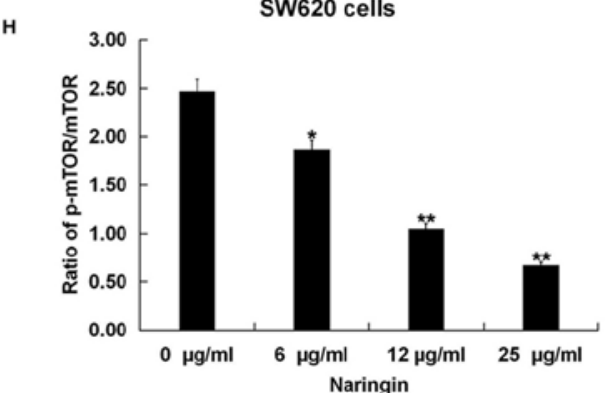

C

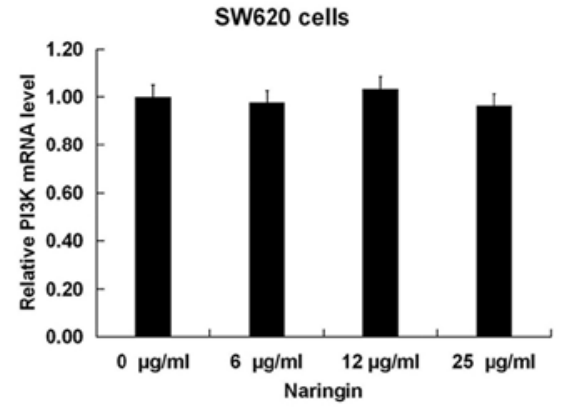

$\mathbf{F}$

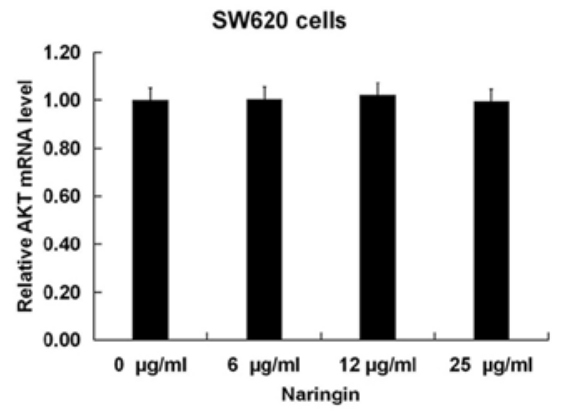

SW620 cells

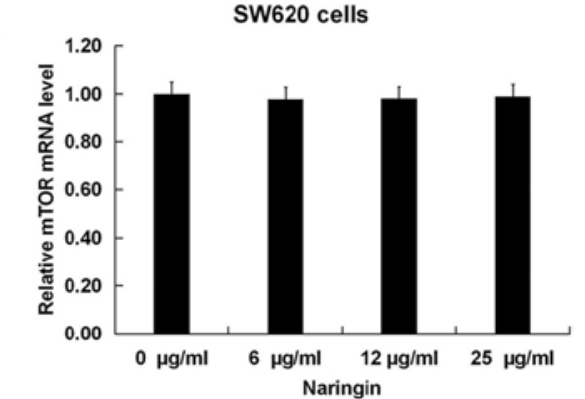

Figure 5. Effect of naringin on the PI3K/AKT/mTOR pathway in SW620 cells. SW620 cells were treated with different concentrations $(6,12$ or $25 \mu \mathrm{g} / \mathrm{ml})$ of naringin for $48 \mathrm{~h}$ at $37^{\circ} \mathrm{C}$. (A) Protein expression levels of PI3K and p-PI3K were detected using western blotting and (B) the ratio of p-PI3K/PI3K was calculated. (C) mRNA expression levels of PI3K were detected using RT-qPCR. (D) Protein expression levels of AKT and p-AKT were detected using western blotting and (E) the ratio of p-AKT/AKT was calculated. (F) mRNA expression levels of AKT were detected using RT-qPCR. (G) Protein expression levels of p-mTOR and p-mTOR were detected using western blotting and (H) the ratio of p-mTOR/mTOR was calculated. (I) mRNA expression levels of mTOR were detected using RT-qPCR. Data are expressed as the mean $\pm \mathrm{SD}$. ${ }^{*} \mathrm{P}<0.05$ and ${ }^{* *} \mathrm{P}<0.01 \mathrm{vs} .0 \mu \mathrm{g} / \mathrm{ml}$ naringin treatment group. p, phosphorylated; RT-qPCR, reverse transcription-quantitative $\mathrm{PCR}$.

of apoptosis. Naringin also increased the expression levels of Bax, a pro-apoptotic protein, in SW620 (Fig. 4A) and HCT116 cells (Fig. 4B).

Naringin effectively inhibits the PI3K/AKT/mTOR signaling pathway. The specific effects of naringin on the $\mathrm{PI} 3 \mathrm{~K} / \mathrm{AKT} / \mathrm{mTOR}$ signaling pathway were investigated in CRC cells. After SW620 and HCT116 cells were treated with serial concentrations of naringin for $48 \mathrm{~h}$, the expression levels of PI3K, phosphorylated (p)-PI3K, AKT, p-AKT, mTOR and p-mTOR were detected using western blot assays. The results showed that there was no significant change in the expression levels of PI3K, AKT and mTOR. However, the expression levels of p-PI3K, p-AKT and p-mTOR were significantly downregulated with increasing naringin concentrations in SW620 (Fig. 5A, D and G) and HCT116 cells (Fig. 6A, D and G). After calculating the ratios of $\mathrm{p}-\mathrm{PI} 3 \mathrm{~K} / \mathrm{PI} 3 \mathrm{~K}, \mathrm{p}-\mathrm{AKT} / \mathrm{AKT}$ and $\mathrm{p}-\mathrm{mTOR} / \mathrm{mTOR}$, it was found that the ratios of these 
A

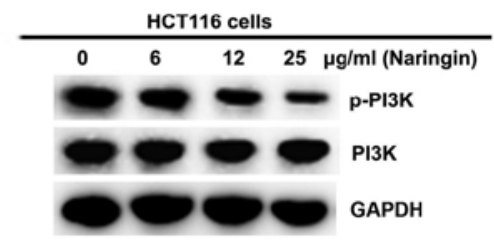

D

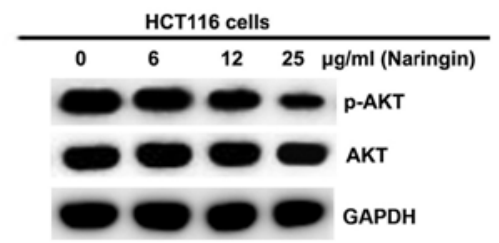

G

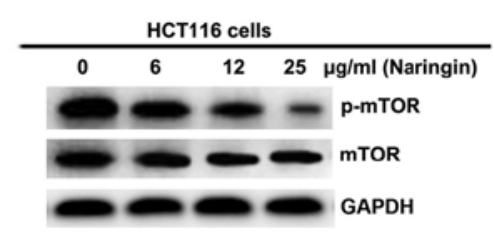

B

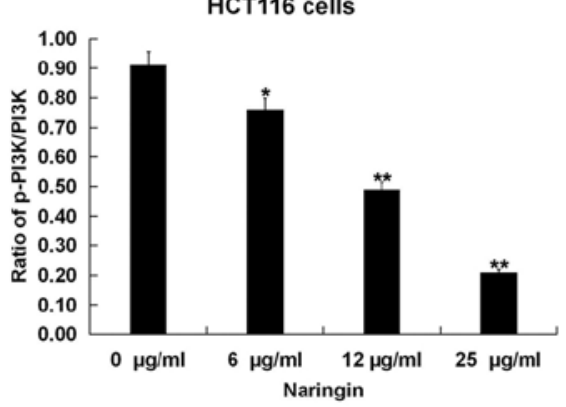

E

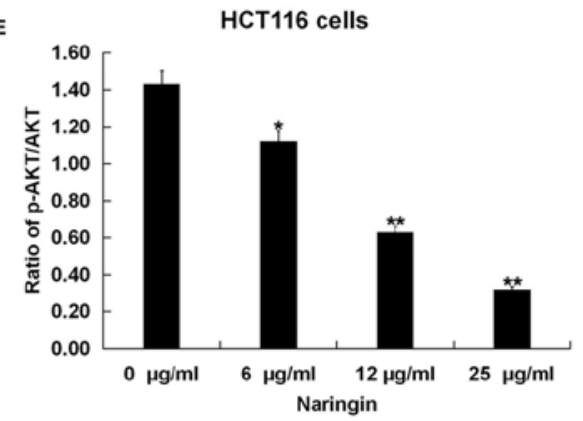

H

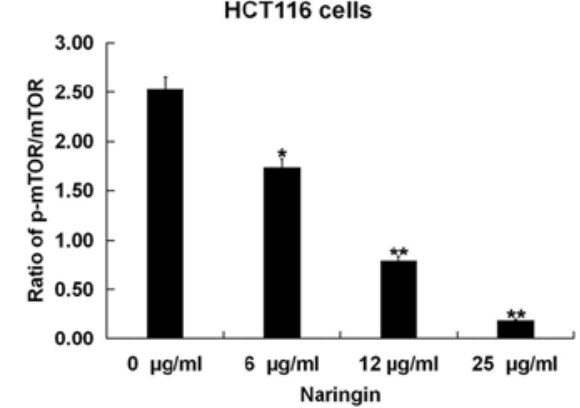

c

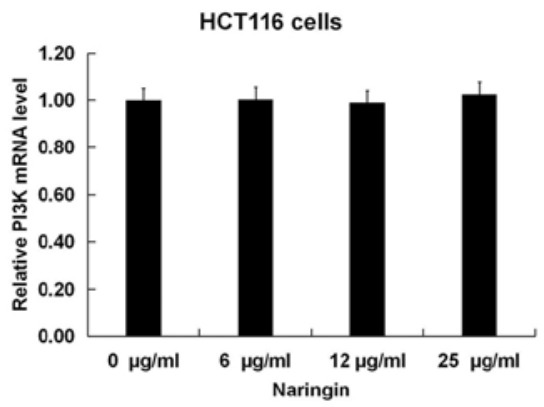

$\mathrm{F}$

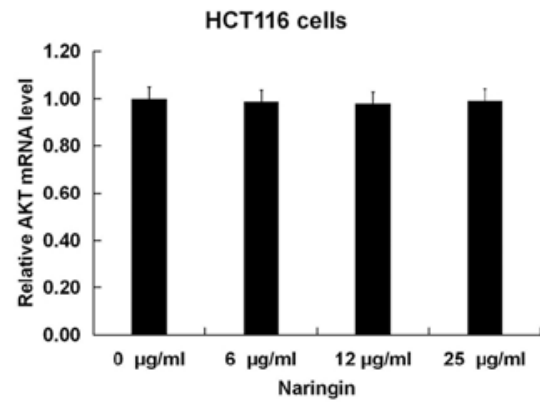

I

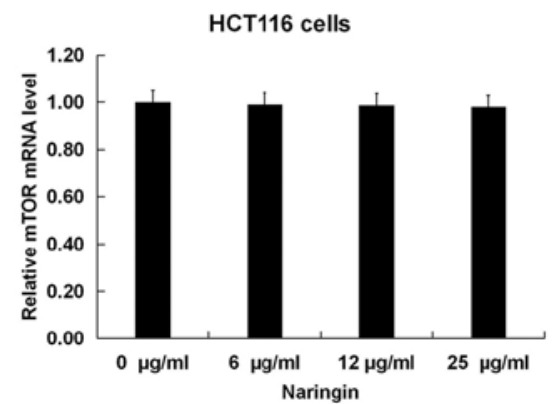

Figure 6. Effect of naringin on the PI3K/AKT/mTOR pathway in HCT116 cells. HCT116 cells were treated with different concentrations $(6,12$ or $25 \mu \mathrm{g} / \mathrm{ml})$ of naringin for $48 \mathrm{~h}$ at $37^{\circ} \mathrm{C}$. (A) Protein expression levels of PI3K and p-PI3K were detected using western blotting and (B) the ratio of p-PI3K/PI3K was calculated. (C) mRNA expression levels of PI3K were detected using RT-qPCR. (D) Protein expression levels of AKT and p-AKT were detected using western blotting and (E) the ratio of p-AKT/AKT was calculated. (F) mRNA expression levels of AKT were detected using RT-qPCR. (G) Protein expression levels of p-mTOR and p-mTOR were detected using western blotting and (H) the ratio of p-mTOR/mTOR was calculated. (I) mRNA expression levels of mTOR were detected using RT-qPCR. Data are expressed as the mean \pm SD. ${ }^{*} \mathrm{P}<0.05$ and ${ }^{* *} \mathrm{P}<0.01 \mathrm{vs}$. $0 \mu \mathrm{g} / \mathrm{ml}$ naringin treatment group. p, phosphorylated; RT-qPCR, reverse transcription-quantitative PCR.

three phosphorylated proteins in SW620 (Fig. 5B, E and H) and HCT116 (Fig. 6B, E and H) cells were downregulated with increasing naringin concentrations. No significant differences were observed in the mRNA expression levels of PI3K, AKT and mTOR in both SW620 (Fig. 5C, F and I) and HCT116 (Fig. 6C, F and I) cells. These results indicated that naringin has a dose-dependent inhibitory effect on the PI3K/AKT/mTOR signaling pathway in CRC cells.

\section{Discussion}

CRC has demonstrated an increasing incidence in recent years (2). For patients with CRC, postoperative ostomy care is difficult and gastrointestinal function is impaired, resulting in a lower quality of life and increasing the extent of pain during subsequent radiotherapy and chemotherapy $(5,6)$. Therefore, investigating new therapeutic methods for treating CRC, new effective compounds and novel signaling pathways have become areas of focus for research in recent years.
Naringin was the compound of focus in the present study. MTT assays were used to detect the proliferation rate of CRC cells treated with naringin. Naringin was found to effectively inhibit CRC cell proliferation in both HCT116 and SW620 cells. Similarly, naringin demonstrated both time- and dose-dependent significant effects on proliferation. Combined with flow cytometry results examining the rate of apoptosis in CRC cells, it was found that naringin had a dose-dependent effect on the apoptosis of CRC cells, with higher doses causing an increase in the extent of apoptosis.

The role of naringin in CRC requires investigation at the molecular level. The PI3K/AKT/mTOR signaling pathway is an important pathway for inhibiting cellular functions $(28,30,31)$. In addition, there are numerous factors that are involved with the PI3K/AKT/mTOR signaling pathway, such as VEGF (32), PTEN (26,30), Bax and Bcl-2 (31). Furthermore, Pandurangan (28) demonstrated that the PI3K/AKT/mTOR signaling pathway is also a potentially effective target for treating CRC. Therefore, western blotting was used to 
investigate the expression levels of Bax, Bcl-2, PI3K, AKT and mTOR.

The western blotting results showed that naringin effectively promoted the expression of Bax, but inhibited the expression of Bcl-2 in a concentration-dependent manner. Elevated expression of Bax is usually associated with apoptosis, while decreased expression levels of $\mathrm{Bcl}-2$ demonstrate a reduced ability to inhibit apoptosis (33). Bax is a pro-apoptotic member of the Bcl-2 family and it is closely related to PI3K pathway $(33,34)$. Molton et al $(35)$ found that CC139 fibroblasts treated with PI3K inhibitors showed a downregulation of Bcl-2. Furthermore, the study showed that the ability of Bax to activate and induce apoptosis was inhibited by the $\mathrm{PI} 3 \mathrm{~K} / \mathrm{AKT} / \mathrm{mTOR}$ signaling pathway (35). According to these results, it can be deduced that the PI3K pathway was suppressed by naringin.

To verify the above inference, western blotting was used to detect changes in the expression levels of PI3K, p-PI3K, AKT, p-AKT, mTOR and p-mTOR. The results showed no significant changes in the expression levels of PI3K, AKT or mTOR, but the expression levels of p-PI3K, p-AKT and p-mTOR showed a dose-dependent decrease when CRC cells were treated with naringin. Similarly, the ratio of p-PI3K/PI3K, p-AKT/AKT and p-mTOR/mTOR also showed a dose-dependent downregulation. A decrease in the expression levels of p-PI3K, p-AKT and p-mTOR demonstrate reduced phosphorylation of $\mathrm{PI} 3 \mathrm{~K}, \mathrm{AKT}$ and $\mathrm{mTOR}$, further indicating that the PI3K/AKT/mTOR signaling pathway had been inhibited. These data also provided strong evidence that naringin may effectively inhibit the proliferation and promote the apoptosis of CRC cells.

Colakoglu et al (27) also observed that the loss of PTEN expression was closely related to the occurrence of CRC. Loss of PTEN expression leads to the activation of AKT and PI3K, which in turn promotes $\beta$-catenin phosphorylation and the malignant proliferation of cancer cells, which is common in cases of CRC (36-38). However, naringin can inhibit this reaction to some extent (39).

In conclusion, the prevention and treatment of CRC through the $\mathrm{PI} 3 \mathrm{~K} / \mathrm{AKT} / \mathrm{mTOR}$ signaling pathway is a feasible direction for future research. naringin inhibited the proliferation of CRC cells and induced apoptosis by inhibiting the $\mathrm{PI} 3 \mathrm{~K} / \mathrm{AKT} / \mathrm{mTOR}$ signaling pathway. Therefore, naringin may be a potential therapeutic agent for the treatment of CRC, which can inhibit the proliferation of CRC cells and induce apoptosis by inhibiting the PI3K/AKT/mTOR signaling pathway.

\section{Acknowledgements}

Not applicable.

\section{Funding}

No funding was received.

\section{Availability of data and materials}

The datasets used and/or analyzed during the current study are available from the corresponding author on reasonable request.

\section{Authors' contributions}

HC, XJ and QZ contributed to study design, data collection, statistical analysis, data interpretation and manuscript preparation. JM, RC, HY, HS, and XZ contributed to data collection and statistical analysis. LG and GG contributed to data collection, statistical analysis and manuscript preparation. All authors read and approved the final manuscript.

\section{Ethics approval and consent to participate}

Not applicable.

\section{Patient consent for publication}

Not applicable.

\section{Competing interests}

The authors declare that they have no competing interests.

\section{References}

1. Torre LA, Bray F, Siegel RL, Ferlay J, Lortet-Tieulent J and Jemal A: Global cancer statistics, 2012. CA Cancer J Clin 65: 87-108, 2015.

2. Gupta N, Kupfer SS and Davis AM: Colorectal Cancer Screening. JAMA 321: 2022-2023, 2019.

3. Kuipers EJ, Grady WM, Lieberman D, Seufferlein T, Sung JJ, Boelens PG, van de Velde CJ and Watanabe T: Colorectal cancer. Nat Rev Dis Primers 1: 15065, 2015.

4. Al-Hajeili M, Marshall JL and Smaglo BG: Neoadjuvant Treatment for Surgically Resectable Metastatic Colorectal Cancer. Oncology (Williston Park) 30: 10-16, 2016.

5. Wang TY, Meng JH and Mai SC: Electroacupuncture Treatment Conduced Before and After Surgery Is Better in Promoting Reco-very of Gastrointestinal Function in Colorectal Cancer Patients Undergoing Radical Resection. Zhen Ci Yan Jiu 43: 797-800, 2018 (Iin Chinese).

6. Drury A, Payne S and Brady AM: The cost of survival: An exploration of colorectal cancer survivors' experiences of pain. Acta Oncol 56: 205-211, 2017.

7. Wang D, Chen J, Chen H, Duan Z, Xu Q, Wei M, Wang L and Zhong M: Leptin regulates proliferation and apoptosis of colorectal carcinoma through PI3K/Akt/mTOR signalling pathway. J Biosci 37: 91-101, 2012.

8. Kocic B, Kitic D and Brankovic S: Dietary flavonoid intake and colorectal cancer risk: Evidence from human population studies. J BUON 18: 34-43, 2013.

9. Jonker DJ, O'Callaghan CJ, Karapetis CS, Zalcberg JR, Tu D, Au HJ, Berry SR, Krahn M, Price T, Simes RJ, et al: Cetuximab for the treatment of colorectal cancer. N Engl J Med 357: 2040-2048, 2007.

10. Van Cutsem E, Köhne CH, Hitre E, Zaluski J, Chang Chien CR, Makhson A, D'Haens G, Pintér T, Lim R, Bodoky G, et al: Cetuximab and chemotherapy as initial treatment for metastatic colorectal cancer. N Engl J Med 360: 1408-1417, 2009.

11. HurwitzH,Fehrenbacher L, Novotny W, Cartwright T, Hainsworth J, Heim W, Berlin J, Baron A, Griffing S, Holmgren E, et al: Bevacizumab plus irinotecan, fluorouracil, and leucovorin for metastatic colorectal cancer. N Engl J Med 350: 2335-2342, 2004.

12. Dienstmann R, De Dosso S, Felip E and Tabernero J: Drug development to overcome resistance to EGFR inhibitors in lung and colorectal cancer. Mol Oncol 6: 15-26, 2012.

13. Van der Jeught K, Xu HC, Li YJ, Lu XB and Ji G: Drug resistance and new therapies in colorectal cancer. World J Gastroenterol 24: 3834-3848, 2018.

14. Frydoonfar HR, McGrath DR and Spigelman AD: The variable effect on proliferation of a colon cancer cell line by the citrus fruit flavonoid Naringenin. Colorectal Dis 5: 149-152, 2003.

15. Chen R, Qi QL, Wang MT and Li QY: Therapeutic potential of naringin: An overview. Pharm Biol 54: 3203-3210, 2016. 
16. Yoshinaga A, Kajiya N, Oishi K, Kamada Y, Ikeda A, Chigwechokha PK, Kibe T, Kishida M,Kishida S, Komatsu M, et al: NEU3 inhibitory effect of naringin suppresses cancer cell growth by attenuation of EGFR signaling through GM3 ganglioside accumulation. Eur J Pharmacol 782: 21-29, 2016.

17. Li H, Yang B, Huang J, Xiang T, Yin X, Wan J, Luo F, Zhang L, $\mathrm{Li} \mathrm{H}$ and Ren G: Naringin inhibits growth potential of human triple-negative breast cancer cells by targeting $\beta$-catenin signaling pathway. Toxicol Lett 220: 219-228, 2013.

18. Zeng L, Zhen Y, Chen Y, Zou L, Zhang Y, Hu F, Feng J, Shen $J$ and Wei B: Naringin inhibits growth and induces apoptosis by a mechanism dependent on reduced activation of $\mathrm{NF}-\kappa \mathrm{B} / \mathrm{COX}-2$-caspase-1 pathway in HeLa cervical cancer cells. Int J Oncol 45: 1929-1936, 2014.

19. Ramesh E and Alshatwi AA: Naringin induces death receptor and mitochondria-mediated apoptosis in human cervical cancer (SiHa) cells. Food Chem Toxicol 51: 97-105, 2013.

20. Raha S, Yumnam S, Hong GE, Lee HJ, Saralamma VV, Park HS Heo JD, Lee SJ, Kim EH, Kim JA, et al: Naringin induces autophagy-mediated growth inhibition by downregulating the $\mathrm{PI} 3 \mathrm{~K} / \mathrm{Akt} / \mathrm{mTOR}$ cascade via activation of MAPK pathways in AGS cancer cells. Int J Oncol 47: 1061-1069, 2015.

21. Morgensztern D and McLeod HL: PI3K/Akt/mTOR pathway as a target for cancer therapy. Anticancer Drugs 16: 797-803, 2005.

22. Scartozzi M, Giampieri R, Maccaroni E, Mandolesi A, Biagetti S Alfonsi S, Giustini L, Loretelli C, Faloppi L, Bittoni A, et al: Phosphorylated AKT and MAPK expression in primary tumours and in corresponding metastases and clinical outcome in colorectal cancer patients receiving irinotecan-cetuximab. J Transl Med 10: 71, 2012.

23. Oikonomou E and Pintzas A: Cancer genetics of sporadic colorectal cancer: BRAF and PI3KCA mutations, their impact on signaling and novel targeted therapies. Anticancer Res 26A: 1077-1084, 2006.

24. Francipane MG and Lagasse E: mTOR pathway in colorectal cancer: An update. Oncotarget 5: 49-66, 2014.

25. Kang S, Dong SM, Kim BR, Park MS, Trink B, Byun HJ and Rho SB: Thioridazine induces apoptosis by targeting the $\mathrm{PI} 3 \mathrm{~K} / \mathrm{Akt} / \mathrm{mTOR}$ pathway in cervical and endometrial cancer cells. Apoptosis17: 989-997,2012.

26. Hamada K, Sasaki T, Koni PA, Natsui M, Kishimoto H, Sasaki J, Yajima N, Horie Y, Hasegawa G, Naito M, et al: The PTEN/PI3K pathway governs normal vascular development and tumor angiogenesis. Genes Dev 19: 2054-2065, 2005.

27. Colakoglu T, Yildirim S, Kayaselcuk F, Nursal TZ, Ezer A, Noyan T, Karakayali H and Haberal M: Clinicopathological significance of PTEN loss and the phosphoinositide 3-kinase/Akt pathway in sporadic colorectal neoplasms: Is PTEN loss predictor of local recurrence? Am J Surg 195: 719-725, 2008.
28. Pandurangan AK: Potential targets for prevention of colorectal cancer: A focus on PI3K/Akt/mTOR and Wnt pathways. Asian Pac J Cancer Prev 14: 2201-2205, 2013.

29. Chen M, Peng W, Hu S and Deng J: miR-126/VCAM-1 regulation by naringin suppresses cell growth of human non-small cell lung cancer. Oncol Lett 16: 4754-4760, 2018.

30. Fang J, Ding M, Yang L, Liu LZ and Jiang BH: PI3K/PTEN/AKT signaling regulates prostate tumor angiogenesis. Cell Signal 19: 2487-2497, 2007.

31. Jiang QG, Li TY, Liu DN and Zhang HT: PI3K/Akt pathway involving into apoptosis and invasion in human colon cancer cells LoVo. Mol Biol Rep 41: 3359-3367, 2014.

32. Falcon BL, Barr S, Gokhale PC, Chou J, Fogarty J, Depeille P, Miglarese M, Epstein DM and McDonald DM: Reduced VEGF production, angiogenesis, and vascular regrowth contribute to the antitumor properties of dual $\mathrm{mTORC} 1 / \mathrm{mTORC} 2$ inhibitors. Cancer Res 71: 1573-1583, 2011.

33. Youle RJ and Strasser A: The BCL-2 protein family: Opposing activities that mediate cell death. Nat Rev Mol Cell Biol 9: 47-59, 2008.

34. Wang Y, Gu J, Hu L, Kong L, Wang T, Di M, Li C and Gui S: miR-130a alleviates neuronal apoptosis and changes in expression of $\mathrm{Bcl}-2 / \mathrm{Bax}$ and caspase-3 in cerebral infarction rats through PTEN/PI3K/Akt signaling pathway. Exp Ther Med 19: 2119-2126, 2020

35. Molton SA, Todd DE and Cook SJ: Selective activation of the c-Jun N-terminal kinase (JNK) pathway fails to elicit Bax activation or apoptosis unless the phosphoinositide 3'-kinase (PI3K) pathway is inhibited. Oncogene 22: 4690-4701, 2003.

36. Ma J, Sawai H, Ochi N, Matsuo Y, Xu D, Yasuda A, Takahashi H, Wakasugi $\mathrm{T}$ and Takeyama $\mathrm{H}$ : PTEN regulates angiogenesis through PI3K/Akt/VEGF signaling pathway in human pancreatic cancer cells. Mol Cell Biochem 331: 161-171, 2009.

37. Primo L, di Blasio L, Roca C, Droetto S, Piva R, Schaffhausen B and Bussolino F: Essential role of PDK1 in regulating endothelial cell migration. J Cell Biol 176: 1035-1047, 2007.

38. Tian T, Nan KJ, Wang SH, Liang X, Lu CX, Guo H, Wang WJ and Ruan ZP: PTEN regulates angiogenesis and VEGF expression through phosphatase-dependent and -independent mechanisms in HepG2 cells. Carcinogenesis 31: 1211-1219, 2010.

39. Erdogan S, Doganlar O, Doganlar ZB and Turkekul K: Naringin sensitizes human prostate cancer cells to paclitaxel therapy. Prostate Int 6: 126-135, 2018

This work is licensed under a Creative Commons Attribution-NonCommercial-NoDerivatives 4.0 International (CC BY-NC-ND 4.0) License. 